\title{
Properties of Aqueous Mixtures of Pure Salts. Thermodynamics of the Ternary System: Water-Calcium Chloride-Magnesium Chloride at $25^{\circ} \mathrm{C}$
}

\author{
R. A. Robinson and V. E. Bower \\ Institute for Materials Research, National Bureau of Standards, Washington, D.C.
}

(March 8, 1966)

\begin{abstract}
Isopiestic vapor pressure measurements have been made on the system water-calcium chloridemagnesium chloride at $25{ }^{\circ} \mathrm{C}$. Activity coefficients have been evaluated for each salt in the presence of the other in systems of constant total ionic strength. The excess free energy of mixing has been calculated and compared with the values for analogous systems.
\end{abstract}

Key Words: Isopiestic measurements, vapor pressure, calcium chloride, mixed solutions, activity coefficients.

\section{Introduction}

The chemical potentials of each solute in an aqueous mixture of two electrolytes have been determined for many systems. For example, the activity coefficients of both hydrochloric acid and sodium chloride in mixed aqueous solution have been derived from emf measurements [1]. ${ }^{1}$ The isopiestic vapor pressure method has been used [2] to determine the activity coefficients of each solute in aqueous mixtures of sodium chloride and potassium chloride. These are two examples of mixtures of uniunivalent electrolytes but considerable work has been done with mixtures of $1: 1$ and $1: 2$ electrolytes. For example, the systems water-hydrochloric acid-barium chloride and water-hydrochloric acid-strontium chloride have been studied by the emf method [3] as have the systems water-hydrochloric acid-calcium chloride and water-hydrochloric acidmanganous chloride [4], while the isopiestic method has been applied to the systems water-sodium chloridebarium chloride [5] and water-potassium chloridebarium chloride [6]. The emf method has been adapted [7] to give trace activity coefficients for the system water-hydrochloric acid-calcium perchlorate, a 'trace' activity coefficient being the limiting value of the activity coefficient of one salt in a solution where its concentration is vanishingly small and the solution contains virtually only the other salt.

The sodium-sensitive glass electrode has been used [8] to study the systems water-sodium chloride-alkaline earth metal chloride. However, there appears to be no case cited in the literature in which solutions of two biunivalent electrolytes have been studied. We now present data for one system of this type, watercalcium chloride-magnesium chloride.

${ }^{1}$ Figures in brackets indicate the literature references at the end of this paper.

\section{Definitions}

$M_{B} \quad$ is the molality (moles per kilogram of solvent) of a solution containing only calcium chloride; it is the molality of the 'reference' solution from which isopiestic data are calculated.

$M_{C} \quad$ is the molality of a solution containing only magnesium chloride, in isopiestic (vaporphase) equilibrium with the calcium chloride solution of molality $M_{B}$.

$m_{B}, m_{C}$ are the molalities of calcium chloride and magnesium chloride, respectively, in a solution containing both these salts and in isopiestic equilibrium with the calcium chloride solution of molality $M_{B}$ and the magnesium chloride solution of molality $\boldsymbol{M}_{C}$.

$R \equiv M_{B} /\left(m_{B}+m_{C}\right)$ is the isopiestic ratio.

$y_{C} \equiv m_{C} /\left(m_{B}+m_{C}\right)$, the ionic fraction, is the fraction of magnesium chloride in the mixture of calcium chloride and magnesium chloride.

$m=m_{B}+m_{C}$.

$\Gamma_{B} \quad$ is the (molal) activity coefficient of calcium chloride in the reference solution of molality $M_{B}$ in equilibrium with the solution containing both calcium chloride and magnesium chloride.

$\Gamma_{C}$ is the activity coefficient of magnesium chloride at molality $M_{C}$ in equilibrium with the reference solution of calcium chloride of molality $M_{B}$.

$\gamma_{B}, \gamma_{C}$ are the activity coefficients of calcium chloride and magnesium chloride, respectively, in the mixed solution, at molalities $m_{B}$ and $m_{C}$.

$\gamma_{B}^{\circ} \quad$ is the activity coefficient of calcium chloride in a solution containing calcium chloride only at the same total ionic strength $I=3 m_{B}+3$ $m_{C}$ as the mixed solution. $\gamma_{C}^{\circ}$ is the activity 
coefficient of magnesium chloride in its own solution at this total ionic strength.

is the osmotic coefficient of calcium chloride in its own solution.

\section{Method}

The result of an isopiestic vapor pressure experiment is the knowledge that a set of solutions of known composition have the same water activity, $a_{W}$. What is needed are the activity coefficients of the two salts in the mixed solution. This is accomplished by means of the McKay-Perring equation [9]:

$\ln \gamma_{B}=\ln \Gamma_{B}+\ln R+\int_{0}^{M_{B} \varphi} f\left(m, M_{B}, y_{C}\right) d\left(M_{B} \varphi\right)$

where

$$
f\left(m, M_{B}, y_{C}\right)=\frac{1}{m^{2}}\left(\frac{\partial m}{\partial \ln y_{C}}\right)_{a_{w}}+\frac{1}{m}-\frac{1}{M_{B}} .
$$

If the isopiestic ratio, $R=M_{B} / m$, can be expressed as:

$$
R=1-a y_{C}-b y_{C}^{2},
$$

the integral reduces to

$$
y_{C}^{2} \int_{0}^{M_{B} \varphi}\left(b / M_{B}\right) d\left(M_{B} \varphi\right)
$$

\section{Materials}

Calcium chloride was prepared from calcium carbonate and hydrochloric acid and recrystallized three times from water slightly acidified with hydrochloric acid. Magnesium chloride was a commercial material, also recrystallızed three times from slightly acidified water.

Each salt was dissolved to make a stock solution whose composition was determined by coulometric titration [10]. ${ }^{2}$ The stock solutions were mixed in suitable proportions to give a series of mixed solutions of known concentrations of calcium chloride and magnesium chloride. The solutions were equilibrated in an isopiestic apparatus in a thermostat at $25 \pm 0.01^{\circ} \mathrm{C}$. The time of equilibration varied from three days for the more concentrated solutions to seven days for the more dilute. The concentrations of the solutions at equilibrium were calculated from the loss or gain of water in each solution.

\section{Results}

The isopiestic data are given in table 1. The second column gives the molality $\left(M_{B}\right)$ of the reference calcium

\begin{tabular}{|c|c|c|c|c|c|c|}
\hline Set & $M_{B}$ & $m_{B}$ & $m_{c}$ & $y_{i}$ & $R$ (obs) & $R$ (calc) \\
\hline \multirow[t]{2}{*}{1} & $0.3121_{1}$ & $\begin{array}{c}0.2213_{4} \\
.0873_{2} \\
.0311_{7}\end{array}$ & $\begin{array}{r}0.0886_{9} \\
.2204_{0} \\
.2753_{5} \\
.3060_{9}\end{array}$ & $\begin{array}{l}0.2860 \\
.7162 \\
.8983 \\
1.0\end{array}$ & $\begin{array}{l}1.0065 \\
1.0143 \\
1.0182 \\
1.0197\end{array}$ & $\begin{array}{l}1.0064 \\
1.0147 \\
1.0178 \\
1.0194\end{array}$ \\
\hline & $0.3166_{2}$ & $\begin{array}{r}0.2717_{5} \\
.1811_{9} \\
.1270_{0}\end{array}$ & $\begin{array}{r}0.0435_{2} \\
.1321_{0} \\
.1853_{1} \\
.3102_{1}\end{array}$ & $\begin{array}{l}0.1380 \\
.4217 \\
.5934 \\
1.0\end{array}$ & $\begin{array}{l}1.0030 \\
1.0094 \\
1.0125 \\
1.0191\end{array}$ & $\begin{array}{l}1.0032 \\
1.0092 \\
1.0126 \\
1.0194\end{array}$ \\
\hline \multirow[t]{3}{*}{2} & $0.5606_{1}$ & $\begin{array}{r}0.5053_{4} \\
.2986_{3} \\
.0808_{9}\end{array}$ & $\begin{array}{r}0.0538_{1} \\
.2545_{5} \\
.4658_{6} \\
.5446_{2}\end{array}$ & $\begin{array}{l}0.0962 \\
.4602 \\
.8521 \\
1.0\end{array}$ & $\begin{array}{l}1.0026 \\
1.0134 \\
1.0253 \\
1.0294\end{array}$ & $\begin{array}{l}1.0031 \\
1.0144 \\
1.0225 \\
1.0294\end{array}$ \\
\hline & 0.5610 & $\begin{array}{r}0.4967_{0} \\
.2805_{9} \\
.1108_{9}\end{array}$ & $\begin{array}{r}0.0621_{6} \\
.2719_{0} \\
.4373_{2} \\
.5450_{9}\end{array}$ & $\begin{array}{l}0.1112 \\
.4921 \\
.7977 \\
1.0\end{array}$ & $\begin{array}{l}1.0040 \\
1.0156 \\
1.0235 \\
1.0294\end{array}$ & $\begin{array}{l}1.0036 \\
1.0154 \\
1.0240 \\
1.0294\end{array}$ \\
\hline & $0.5625^{\prime}$ & $\begin{array}{r}0.3862_{1} \\
.1734_{\omega} \\
.0519_{1}\end{array}$ & $\begin{array}{r}0.1705_{2} \\
.3772_{7} \\
.4957_{2} \\
.5463_{2}\end{array}$ & $\begin{array}{l}0.3063 \\
.6851 \\
.9052 \\
1.0\end{array}$ & $\begin{array}{l}1.0104 \\
1.0215 \\
1.0272 \\
1.0296\end{array}$ & $\begin{array}{l}1.0098 \\
1.0209 \\
1.0269 \\
1.0294\end{array}$ \\
\hline \multirow[t]{2}{*}{3} & 1.0135 & $\begin{array}{r}0.8706 \\
.6079 \\
.2680\end{array}$ & $\begin{array}{r}0.1367 \\
.3875 \\
.7126 \\
.9700\end{array}$ & $\begin{array}{l}0.1357 \\
.3893 \\
.7267 \\
1.0\end{array}$ & $\begin{array}{l}1.0062 \\
1.0182 \\
1.0336 \\
1.0448\end{array}$ & $\begin{array}{l}1.0066 \\
1.0185 \\
1.0333 \\
1.0444\end{array}$ \\
\hline & 1.0198 & $\begin{array}{r}0.7503 \\
.3767 \\
.1597\end{array}$ & $\begin{array}{r}0.2561 \\
.6146 \\
.8231 \\
.9767\end{array}$ & $\begin{array}{r}0.2545 \\
.6200 \\
.8375 \\
1.0\end{array}$ & $\begin{array}{l}1.0133 \\
1.0288 \\
1.0376 \\
1.0441\end{array}$ & $\begin{array}{l}1.0123 \\
1.0288 \\
1.0379 \\
1.0444\end{array}$ \\
\hline \multirow[t]{2}{*}{4} & 1.5003 & $\begin{array}{r}1.3154 \\
0.9250 \\
.3715\end{array}$ & $\begin{array}{r}0.1720 \\
.5426 \\
1.0665 \\
1.4191\end{array}$ & $\begin{array}{l}0.1156 \\
.3697 \\
.7417 \\
1.0\end{array}$ & $\begin{array}{l}1.0087 \\
1.0223 \\
1.0443 \\
1.0572\end{array}$ & $\begin{array}{l}1.0072 \\
1.0226 \\
1.0438 \\
1.0575\end{array}$ \\
\hline & 1.5109 & $\begin{array}{r}1.1952 \\
0.6434 \\
.2367\end{array}$ & $\begin{array}{r}0.2975 \\
.8190 \\
1.2045 \\
1.4291\end{array}$ & $\begin{array}{c}0.1993 \\
.5600 \\
.8358 \\
1.0\end{array}$ & $\begin{array}{l}1.0122 \\
1.0332 \\
1.0484 \\
1.0572\end{array}$ & $\begin{array}{l}1.0124 \\
1.0337 \\
1.0490 \\
1.0575\end{array}$ \\
\hline \multirow[t]{2}{*}{5} & 1.8445 & $\begin{array}{r}1.3317 \\
0.7829 \\
.2943\end{array}$ & $\begin{array}{r}0.4793 \\
.9961 \\
1.4582 \\
1.7347\end{array}$ & $\begin{array}{l}0.2647 \\
.5599 \\
.8321 \\
1.0\end{array}$ & $\begin{array}{l}1.0185 \\
1.0368 \\
1.0525 \\
1.0633\end{array}$ & $\begin{array}{l}1.0180 \\
1.0370 \\
1.0537 \\
1.0635\end{array}$ \\
\hline & 1.8588 & $\begin{array}{r}1.5716 \\
0.9977 \\
.6212\end{array}$ & $\begin{array}{r}0.2671 \\
.8067 \\
1.1618 \\
1.7475\end{array}$ & $\begin{array}{l}0.1453 \\
.4471 \\
.6516 \\
1.0\end{array}$ & $\begin{array}{l}1.0109 \\
1.0301 \\
1.0425 \\
1.0637\end{array}$ & $\begin{array}{l}1.0100 \\
1.0299 \\
1.0427 \\
1.0635\end{array}$ \\
\hline \multirow[t]{2}{*}{6} & 2.1878 & $\begin{array}{l}1.7890 \\
1.2674 \\
0.6155\end{array}$ & $\begin{array}{r}0.3724 \\
.8604 \\
1.4722 \\
2.0500\end{array}$ & $\begin{array}{l}0.1723 \\
.4044 \\
.7052 \\
1.0\end{array}$ & $\begin{array}{l}1.0122 \\
1.0282 \\
1.0479 \\
1.0672\end{array}$ & $\begin{array}{l}1.0123 \\
1.0285 \\
1.0487 \\
1.0675\end{array}$ \\
\hline & 2.2088 & $\begin{array}{r}1.5047 \\
0.8663 \\
.3369\end{array}$ & $\begin{array}{l}0.6568 \\
1.2539 \\
1.7515 \\
2.0686\end{array}$ & $\begin{array}{l}0.3039 \\
.5914 \\
.8387 \\
1.0\end{array}$ & $\begin{array}{l}1.0219 \\
1.0418 \\
1.0576 \\
1.0678\end{array}$ & $\begin{array}{l}1.0216 \\
1.0411 \\
1.0573 \\
1.0675\end{array}$ \\
\hline \multirow[t]{2}{*}{7} & 2.4524 & $\begin{array}{l}1.7806 \\
1.0056 \\
0.3413\end{array}$ & $\begin{array}{l}0.6237 \\
1.3486 \\
1.9706 \\
2.2908\end{array}$ & $\begin{array}{l}0.2594 \\
.5728 \\
.8524 \\
1.0\end{array}$ & $\begin{array}{l}1.0200 \\
1.0417 \\
1.0608 \\
1.0705\end{array}$ & $\begin{array}{l}1.0194 \\
1.0418 \\
1.0609 \\
1.0706\end{array}$ \\
\hline & 2.4732 & $\begin{array}{l}2.0969 \\
1.4318 \\
0.6916\end{array}$ & $\begin{array}{r}0.3488 \\
.9697 \\
1.6634 \\
2.3101\end{array}$ & $\begin{array}{l}0.1426 \\
.4038 \\
.7063 \\
1.0\end{array}$ & $\begin{array}{l}1.0112 \\
1.0299 \\
1.0502 \\
1.0706\end{array}$ & $\begin{array}{l}1.0108 \\
1.0299 \\
1.0511 \\
1.0706\end{array}$ \\
\hline \multirow[t]{2}{*}{8} & 2.6919 & $\begin{array}{l}1.8448 \\
1.2071 \\
0.4020\end{array}$ & $\begin{array}{l}0.7859 \\
1.3810 \\
2.1294 \\
2.5076\end{array}$ & $\begin{array}{l}0.2987 \\
.5336 \\
.8412 \\
1.0\end{array}$ & $\begin{array}{l}1.0233 \\
1.0401 \\
1.0634 \\
1.0735\end{array}$ & $\begin{array}{l}1.0235 \\
1.0411 \\
1.0631 \\
1.0739\end{array}$ \\
\hline & 2.6952 & $\begin{array}{l}2.2653 \\
1.4165 \\
0.7960\end{array}$ & $\begin{array}{l}0.3962 \\
1.1869 \\
1.7646 \\
2.5091\end{array}$ & $\begin{array}{c}0.1489 \\
.4559 \\
.6891 \\
1.0\end{array}$ & $\begin{array}{l}1.0127 \\
1.0353 \\
1.0526 \\
1.0742\end{array}$ & $\begin{array}{l}1.0119 \\
1.0354 \\
1.0524 \\
1.0739\end{array}$ \\
\hline \multirow[t]{2}{*}{9} & 3.2040 & $\begin{array}{l}2.7101 \\
1.9225 \\
0.8894\end{array}$ & $\begin{array}{l}0.4556 \\
1.1860 \\
2.1444 \\
2.9707\end{array}$ & $\begin{array}{l}0.1439 \\
.3815 \\
.7068 \\
1.0\end{array}$ & $\begin{array}{l}1.0121 \\
1.0307 \\
1.0561 \\
1.0785\end{array}$ & $\begin{array}{l}1.0116 \\
1.0305 \\
1.0559 \\
1.0783\end{array}$ \\
\hline & 3.2061 & $\begin{array}{l}2.3272 \\
1.2844 \\
0.5007\end{array}$ & $\begin{array}{l}0.8130 \\
1.7808 \\
2.5079 \\
2.9736\end{array}$ & $\begin{array}{l}0.2589 \\
.5810 \\
.8336 \\
1.0\end{array}$ & $\begin{array}{l}1.0210 \\
1.0460 \\
1.0656 \\
1.0782\end{array}$ & $\begin{array}{l}1.0208 \\
1.0462 \\
1.0657 \\
1.0783\end{array}$ \\
\hline
\end{tabular}

2 The analyses were made by George Marinenko of the Analysis and Purification Section.
TABLE 1. Isopiestic data for the system $\mathrm{H}_{2} \mathrm{O}-\mathrm{CaCl}_{2}-\mathrm{MgCl}_{2}$ at $25^{\circ} \mathrm{C}^{\mathrm{a}}$ 
TABLE 1. Isopiestic data for the system $\mathrm{H}_{2} \mathrm{O}-\mathrm{CaCl}_{2}-\mathrm{MgCl}_{2}$ at $25{ }^{\circ} \mathrm{C}^{\mathrm{a}}$ - Continued

\begin{tabular}{|c|c|c|c|c|c|c|}
\hline Set & $M_{B}$ & $m_{B}$ & $m_{C}$ & $y_{C}$ & $R$ (obs) & $R(\mathrm{calc})$ \\
\hline \multirow[b]{2}{*}{10} & 3.2213 & $\begin{array}{l}2.2712 \\
1.4070 \\
0.4583\end{array}$ & $\begin{array}{l}0.8798 \\
1.6816 \\
2.5623 \\
2.9878\end{array}$ & $\begin{array}{c}0.2792 \\
.5445 \\
.8483 \\
1.0\end{array}$ & $\begin{array}{l}1.0223 \\
1.0430 \\
1.0664 \\
1.0782\end{array}$ & $\begin{array}{l}1.0224 \\
1.0433 \\
1.0668 \\
1.0783\end{array}$ \\
\hline & 3.5888 & $\begin{array}{l}3.0616 \\
2.0524 \\
1.0121 \\
\\
2.5711 \\
1.4668 \\
0.5128\end{array}$ & $\begin{array}{l}0.4646 \\
1.4035 \\
2.3665 \\
3.3044 \\
0.9401 \\
1.9622 \\
2.8425 \\
3.3214\end{array}$ & $\begin{array}{l}0.1318 \\
.4061 \\
.7005 \\
1.0 \\
0.2677 \\
.5722 \\
.8472 \\
1.0\end{array}$ & $\begin{array}{l}1.0121 \\
1.0327 \\
1.0563 \\
1.0804 \\
1.0221 \\
1.0466 \\
1.0696 \\
1.0815\end{array}$ & $\begin{array}{l}1.0111 \\
1.0337 \\
1.0573 \\
1.0806 \\
1.0224 \\
1.0471 \\
1.0688 \\
1.0806\end{array}$ \\
\hline 11 & 3.8882 & $\begin{array}{l}2.7993 \\
1.0923 \\
0.5415\end{array}$ & $\begin{array}{l}1.0036 \\
2.5829 \\
3.0903 \\
3.5925\end{array}$ & $\begin{array}{c}0.2639 \\
.7028 \\
.8509 \\
1.0\end{array}$ & $\begin{array}{l}1.0224 \\
1.0580 \\
1.0706 \\
1.0823\end{array}$ & $\begin{array}{l}1.0221 \\
1.0583 \\
1.0703 \\
1.0825\end{array}$ \\
\hline \multirow{3}{*}{12} & 3.8898 & $\begin{array}{l}3.3050 \\
2.2317 \\
1.6526\end{array}$ & $\begin{array}{l}0.5388 \\
1.5309 \\
2.0654 \\
3.5924\end{array}$ & $\begin{array}{c}0.1402 \\
.4069 \\
.5555 \\
1.0\end{array}$ & $\begin{array}{l}1.0120 \\
1.0338 \\
1.0462 \\
1.0828\end{array}$ & $\begin{array}{l}1.0118 \\
1.0340 \\
1.0463 \\
1.0825\end{array}$ \\
\hline & 4.1086 & $\begin{array}{l}2.9954 \\
1.7642 \\
0.6953\end{array}$ & $\begin{array}{l}1.0244 \\
2.1606 \\
3.1471 \\
3.7860\end{array}$ & $\begin{array}{c}0.2548 \\
.5505 \\
.8190 \\
1.0\end{array}$ & $\begin{array}{l}1.0221 \\
1.0468 \\
1.0693 \\
1.0852\end{array}$ & $\begin{array}{l}1.0219 \\
1.0472 \\
1.0700 \\
1.0854\end{array}$ \\
\hline & 4.1220 & $\begin{array}{l}3.5742 \\
2.3894 \\
1.1896\end{array}$ & $\begin{array}{l}0.5018 \\
1.5948 \\
2.7009 \\
3.7967\end{array}$ & $\begin{array}{c}0.1231 \\
.4003 \\
.6942 \\
1.0\end{array}$ & $\begin{array}{l}1.0113 \\
1.0346 \\
1.0595 \\
1.0857\end{array}$ & $\begin{array}{l}1.0106 \\
1.0343 \\
1.0594 \\
1.0854\end{array}$ \\
\hline
\end{tabular}

${ }^{\text {a }} B=\mathrm{CaCl}_{2}, C=\mathrm{MgCl}_{2} . \quad y_{C}=m_{C} /\left(m_{B}+m_{C}\right) . \quad R=M_{B} /\left(m_{B}+m_{C}\right) . \quad R($ calc $)$ is calculated by means of eq (3) with the values of the parameters given in table 2 .

chloride solution, the third and fourth column give values of the molalities of calcium chloride $\left(m_{B}\right)$ and magnesium chloride $\left(m_{C}\right)$ in the mixed solutions isopiestic with the reference solution. The next column gives the fraction of magnesium chloride, $y_{C}=m_{C} / m$, in the mixture and the next the observed isopiestic ratio, $R=M_{B} / m$. Plots of these isopiestic ratios, some of which are shown in figure 1, exhibit a slight curvature, more marked in the more dilute solutions. The data were therefore fitted to eq (3) by the method of least squares. The last column of table 1 gives values of the isopiestic ratio calculated by eq (3) with the parameters given in table 2 .

\section{Calculations of Activity Coefficients}

The application of eq (1) requires a knowledge of three quantities. $\Gamma_{B}$ (or $\Gamma_{C}$ in the corresponding equation for $\gamma_{C}$ ) can be obtained directly from tables of the activity coefficient of calcium chloride (or magnesium chloride) in its own solution [11]. The isopiestic ratio, $R$, has already been recorded in table 1 . It is in the evaluation of the integral in eq (1) that some difficulty is encountered. Figure 2 is a plot of $b / M_{B}$ against $\left(M_{B} \varphi\right)$, omitting the point at $M_{B}=0.3142$ which

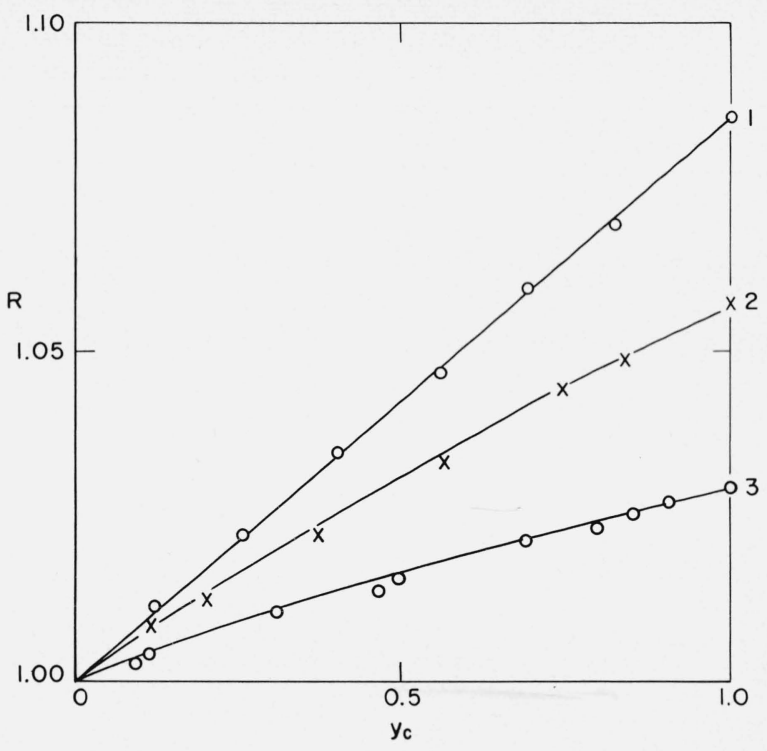

FIGUKE 1. Isodiestic ratio, $\mathrm{R}=\mathrm{M}_{\mathrm{B}} /\left(\mathrm{m}_{\mathrm{B}}+\mathrm{m}_{\mathrm{C}}\right)$ of calcium chloridemagnesium chloride solutions versus tonic fraction, $\mathrm{y}_{C}=\mathrm{m}_{\mathrm{C}} /\left(\mathrm{m}_{\mathrm{B}}+\mathrm{m}_{\mathrm{C}}\right)$. 1. $M_{B}=4.1183$. 2. $M_{B}=2.1983$. 3. $M_{B}=0.5614$.

TABLE 2. Values of the parameters of eq (3)

\begin{tabular}{|c|c|c|c|c|c|}
\hline Set & $M_{B}$ & $M_{B} \varphi$ & $a$ & $b$ & $b / M_{B}$ \\
\hline 1 & 0.3142 & 0.276 & -0.0234 & 0.0040 & 0.0127 \\
\hline 2 & $\begin{array}{l}.5614 \\
.5614\end{array}$ & $\begin{array}{r}.210 \\
.523\end{array}$ & $\begin{array}{r}-.0330 \\
-.030\end{array}$ & .0036 & .0064 \\
\hline 3 & 1.0167 & 1.069 & -.0497 & .0053 & .0052 \\
\hline 4 & 1.5056 & 1.816 & -.0634 & .0059 & .0039 \\
\hline 5 & 1.8517 & 2.451 & -.0695 & .0060 & .0026 \\
\hline 6 & 2.1983 & 3.192 & -.0725 & .0050 & .0023 \\
\hline 7 & 2.4628 & 3.827 & -.0763 & .0057 & .0023 \\
\hline 8 & 2.6936 & 4.444 & -.0808 & .0069 & .0026 \\
\hline $\begin{array}{l}0 \\
9\end{array}$ & 3.2105 & 5.989 & -.0811 & .0028 & .0009 \\
\hline 10 & 3.5789 & 7.203 & -.0847 & .0041 & .0011 \\
\hline 11 & 3.8890 & 8.312 & -.0842 & .0017 & .0005 \\
\hline 12 & 4.1183 & 9.177 & -.0861 & .0007 & .0002 \\
\hline
\end{tabular}

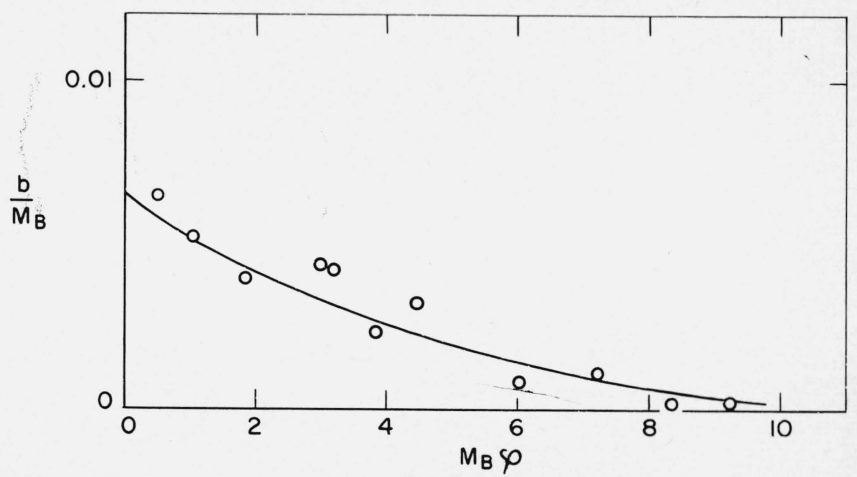

Figure 2. $\mathrm{b} / \mathrm{M}_{\mathrm{B}}$ versus $\mathrm{M}_{\mathrm{B}} \varphi$. 
is badly off the curve. This is not surprising for accurate isopiestic results are difficult to obtain at low concentrations. The curve drawn in figure 2 is that of the equation:

$b / M_{B}=0.0066-0.00144\left(M_{B} \varphi\right)+0.000084\left(M_{B} \varphi\right)^{2}$

so that the integral in eq (1) is given by:

$y_{C}^{2}\left(M_{B} \varphi\right)\left[0.0066-0.00072\left(M_{B} \varphi\right)+0.000028\left(M_{B} \varphi\right)^{2}\right]$

or, multiplying by 0.4343 if eq (1) is to be used with decadic logarithms:

$y_{C}^{2}\left(M_{B} \varphi\right)\left[0.0029-0.00031\left(M_{B} \varphi\right)+0.000012\left(M_{B} \varphi\right)^{2}\right]$.

The maximum value of this integral which will be used is at $y_{C}=1, M_{B}=4.1183,\left(M_{B} \varphi\right)=9.177$. The integral then has the value 0.0096 , which is much smaller than the other term, $\log R=0.0356$.

The calculation of activity coefficients in mixed salt solutions may be illustrated as follows. One result from set 8 in table 1 concerns a reference solution of calcium chloride of molality $M_{B}=2.6919$. The value of $\log \Gamma_{B}$ for calcium chloride in its own solution at this concentration is 0.0820 . This solution was in isopiestic equilibrium with a mixed solution containing calcium chloride at molality $m_{B}=0.4020$ and magnesium chloride at molality $m_{C}=2.1294$; the total molality of the solution was $m=2.5314$ with $y_{C}=0.8412$. The isopiestic ratio for this solution was found to be $R=1.0631$ or $\log R=0.0266$. Substitution gives $0.0076 y_{C}^{2}=0.0054$ as the contribution of the integral term in eq (1). Hence we find $\log \gamma_{B}$ $=0.1140$. We have now found the activity coefficient of calcium chloride in a mixed solution of total molality $m=2.5314$. But $\log \gamma_{B}^{\circ}$ for calcium chloride alone in its own solution at this concentration is 0.0355 and therefore $\log \gamma_{B} / \gamma_{B}^{\circ}$ is 0.0785 . Making similar calculations for all the solutions in this set of data, we get the results shown in table 3 . Figure 3 is a plot of log $\gamma_{B} / \gamma_{B}^{\circ}$ against $m_{c}$ from which it can be seen that a straight line represents the variation of $\log \gamma_{B} / \gamma_{B}^{\circ}$ very well. The last column of table 3 gives values obtained by means of the equation

$$
\log \gamma_{B}=\log \gamma_{B}^{\circ}+0.0366 m_{C} .
$$

The agreement is good and it follows that Harned's rule:

$$
\log \gamma_{B}=\log \gamma_{B}^{\circ}-\alpha_{B} m_{C}
$$

holds with $\alpha_{B}=-0.0366$. An equally good straight line plot is obtained for the variation of $\log \gamma_{C}$ with $m_{B}$,

$$
\log \gamma_{C}=\log \gamma_{C}^{\circ}-\alpha_{C} m_{B}
$$

with $\alpha_{C}=0.0331$.
TABLE 3. Variation of $\log \gamma_{\mathrm{B}}$ with magnesium chloride concentration at a total molality of about 2.5

\begin{tabular}{l|r|r|r|r}
\hline \hline$m_{B}$ & \multicolumn{1}{|c|}{$m_{C}$} & \multicolumn{1}{c|}{$m$} & $\log \gamma_{B} / \gamma_{B}^{\circ}$ & $\log \gamma_{B} / \gamma_{B}^{\circ}(\mathrm{calc})^{a}$ \\
\hline & & & & \\
2.2652 & 0.3962 & 2.6614 & 0.0151 & 0.0145 \\
1.8448 & .7859 & 2.6307 & .0284 & .0288 \\
1.4165 & 1.1869 & 2.6034 & .0433 & .0435 \\
1.2071 & 1.3810 & 2.5881 & .0498 & .0506 \\
0.7960 & 1.7646 & 2.5606 & .0646 & .0647 \\
.4020 & 2.1294 & 2.5314 & .0785 & .0780 \\
0 & 2.5091 & 2.5091 & .0924 & .0919 \\
0 & 2.5076 & 2.5076 & .0918 & .0919 \\
\hline
\end{tabular}

Harned's rule, however, is usually applied to systems at constant total ionic strength, $I=3 m_{B}+3 m_{c}$ $=3 m$, and inspection of table 3 shows that $m$ is not quite constant, varying from 2.5076 to 2.6614 . It will be shown later that $\alpha_{B}$ varies only slowly with $m$, and the slight departure from exact constancy of the total ionic strength is without appreciable effect on the value of $\alpha_{B}$.

Similar calculations of the values of $\alpha_{B}$ and $\alpha_{C}$ have been made for the other sets of results in table 1 . These values are given in table 4 along with values of $\left(\alpha_{B}+\alpha_{C}\right)$. These values are also plotted in figure 4 . If the behavior of this system were more complicated than that represented by eq (8) and eq (9), for example, if

$$
\begin{aligned}
& \log \gamma_{B}=\log \gamma_{B}^{\circ}-\alpha_{B} m_{C}-\beta_{B} m_{C}^{2} \\
& \log \gamma_{C}=\log \gamma_{C}^{\circ}-\alpha_{C} m_{B}-\beta_{C} m_{B}^{2}
\end{aligned}
$$

there is a relation between these $\alpha$ and $\beta$ coefficients. We developed a general form of this relation in the appendix to a previous paper [5]; for a system of the calcium chloride-magnesium chloride type this takes the form

$$
\left(\alpha_{B}+\alpha_{C}\right)=\text { constant }-2\left(\beta_{B}+\beta_{C}\right) m .
$$

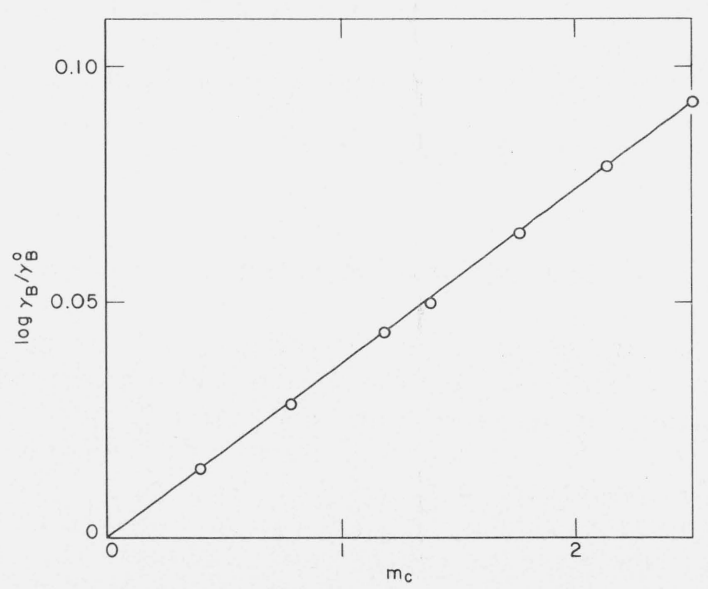

FIGURE 3. Variation of the activity coefficient of calcium chloride on addition of magnesium chloride $\mathrm{M}_{\mathrm{B}}=2.2636$. 
TABLE 4. Values of the parameters $\alpha_{B}$ and $\alpha_{C}$ of eq (8) and eq (9)

\begin{tabular}{c|c|r|r}
\hline \hline$M_{B}$ & $\alpha_{B}$ & \multicolumn{1}{|c|}{$\alpha_{C}$} & $\left(\alpha_{B}+\alpha_{C}\right)$ \\
\hline & & & \\
0.3142 & -0.0277 & 0.0225 & -0.0052 \\
.5614 & -.0270 & .0225 & -.0045 \\
1.0167 & -.0288 & .0250 & -.0038 \\
1.5056 & -.0314 & .0279 & -.0035 \\
1.8517 & -.0326 & .0288 & -.0038 \\
2.1983 & -.0338 & .0314 & -.0024 \\
2.4628 & -.0336 & .0310 & -.0026 \\
2.6936 & -.0366 & .0331 & -.0035 \\
3.2105 & -.0366 & .0346 & -.0020 \\
3.5789 & -.0363 & .0348 & -.0015 \\
3.8870 & -.0364 & .0363 & -.0001 \\
4.1183 & -.0370 & .0373 & +.0003 \\
\hline
\end{tabular}

Thus the sum $\left(\alpha_{B}+\alpha_{C}\right)$ is independent of the total molality only if either both $\beta_{B}$ and $\beta_{C}$ are zero or else $\beta_{B}$ and $\beta_{C}$ are equal and opposite in sign. Inspection of figure 4 shows that $\left(\alpha_{B}+\alpha_{C}\right)$ does vary slightly with the total molality; this variation could be accounted for by ascribing a value of -0.0006 to $\left(\beta_{B}\right.$ $\left.+\beta_{C}\right)$ or -0.0003 to both $\beta_{B}$ and $\beta_{C}$. This would mean a slight curvature in figure 3 but it is so small that it would be difficult to detect experimentally.

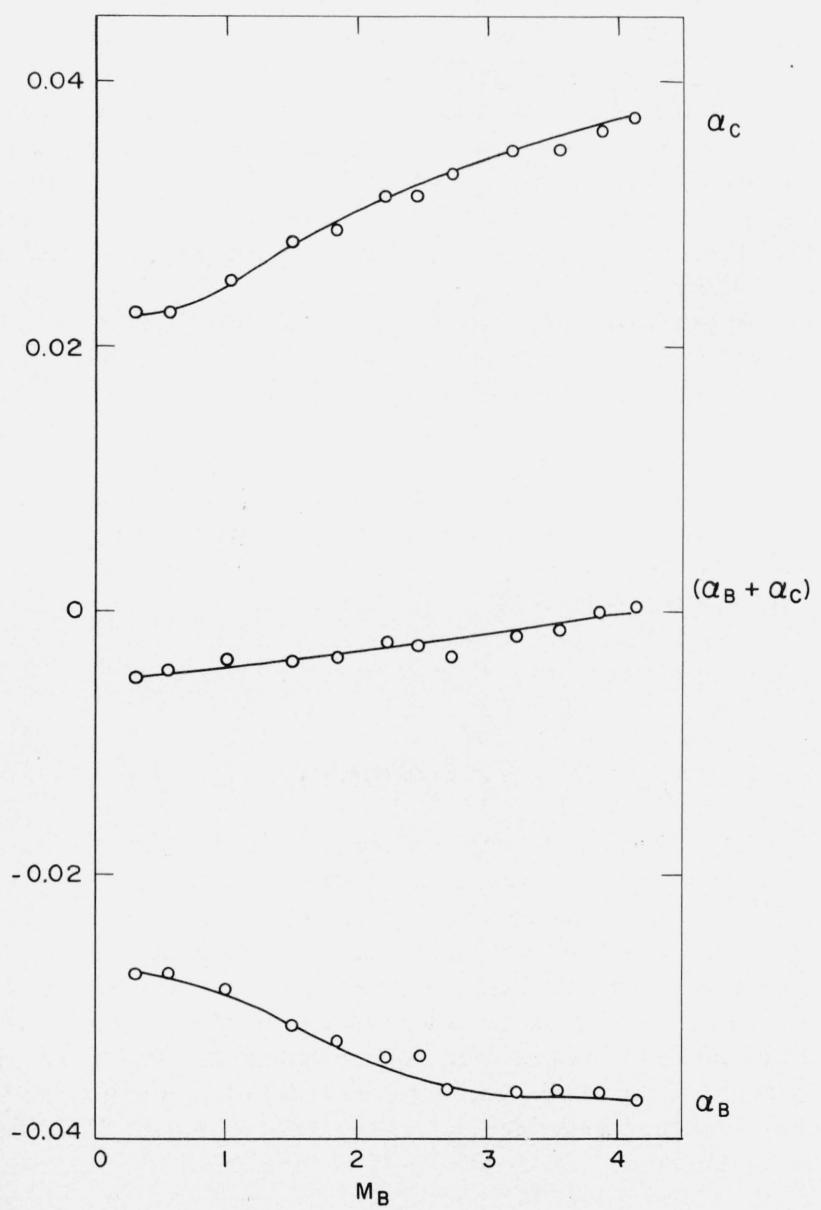

Figure 4. $\alpha_{\mathrm{B}}, \alpha_{\mathrm{C}}$ and $\left(\alpha_{\mathrm{B}}+\alpha_{\mathrm{C}}\right)$ versus $\mathrm{M}_{\mathrm{B}}$.
The fact that $\alpha_{C}$ is numerically positive means that $\log \gamma_{C}$ decreases on the replacement of magnesium chloride by calcium chloride at constant total molality. Conversely, $\log \gamma_{B}$ increases when calcium chloride is replaced by magnesium chloride at constant total molality. For example, the activity coefficient of magnesium chloride in its own solution at $4 \mathrm{~m}$ is 5.53; in a solution containing $2 \mathrm{~m}$ magnesium chloride and $2 \mathrm{~m}$ calcium chloride it is 4.67 and in the limiting case where magnesium chloride is present in vanishingly small amount in $4 \mathrm{~m}$ calcium chloride solution it is 3.93. The activity coefficient of calcium chloride in its own solution at $4 \mathrm{~m}$ is 2.93 ; in a solution containing $2 \mathrm{~m}$ magnesium chloride and $2 \mathrm{~m}$ calcium chloride it is 3.48 and the 'trace' activity coefficient in $4 \mathrm{~m}$ magnesium chloride solution is 4.13 (fig. 5). Thus the trace activity coefficients, the activity coefficient of one salt when the other preponderates in concentration, are almost the same, 3.93 for magnesium chloride and 4.13 for calcium chloride. The same is true at other concentrations. At a total molality of $m=2$, the activity coefficient of magnesium chloride, 1.051, is lowered to 0.915 , the 'trace' activity coefficient in $2 \mathrm{~m}$ calcium chloride solution. On the contrary, the activity coefficient of calcium chloride, which is 0.792 in its own solution, is raised to 0.924 in $2 m$ magnesium chloride solution. The corresponding changes at $0.3 \mathrm{~m}$ are from 0.476 to 0.469 for magnesium chloride and from 0.455 to 0.464 for calcium chloride.

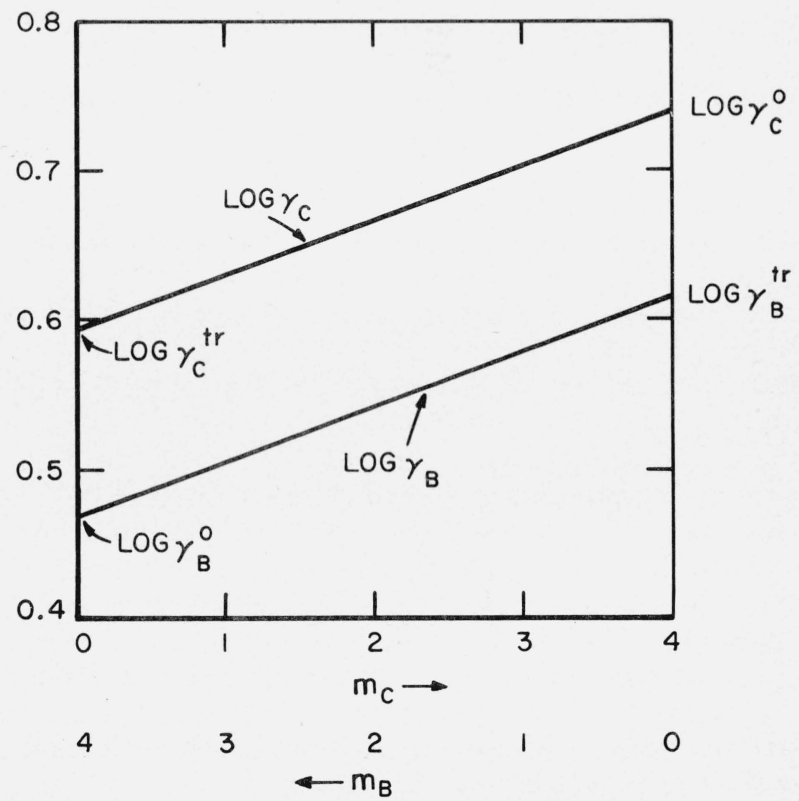

FIGURE 5. Activity coefficients of calcium chloride and magnesium chloride in mixed aqueous solution at constant total ionic concentration of $4 m(\mathrm{I}=12)$. $\gamma^{\circ}=$ Activity coefficient of a salt in its own solution.
$\gamma^{\mathrm{tr}}=$ "Trace" activity coefficient of one salt in a solution of the other salt. 


\section{Excess Free Energy of Mixing}

If a solution of $y_{B} m$ moles of calcium chloride in $\mathrm{y}_{B} \mathrm{~kg}$ of water is mixed with a solution of $y_{C} m$ moles of magnesium chloride in $y_{C} \mathrm{~kg}$ of water, the resulting solution will consist of $y_{B} m$ moles of calcium chloride and $y_{C} m$ moles of magnesium chloride in a kilogram of water. There will be no change in total molality, $m$, during the process of mixing. The change in free energy during the mixing process will contain an entropy term of the form $3 R \operatorname{Rm}\left[y_{B} \ln v_{B}+y_{C} \ln y_{C}\right]$, an expression which appears even if all three solutions are ideal. It is therefore ignored in calculating the excess free energy of mixing; the excess free energy is that due to departures from ideality of both solvent and solutes. A general equation for this excess free energy of mixing has been developed in the appendix to an earlier paper [6] which, for the calcium chloridemagnesium chloride system, takes the form

$$
\frac{\Delta G^{E}}{2.3026 R T}=-\frac{3}{2} \cdot m_{B} m_{C}\left(\alpha_{B}+\alpha_{C}\right)
$$

The maximum excess free energy is found when $m_{B}$ $=m_{C}=0.5 m, y_{B}=y_{C}=0.5$,

$$
\frac{\Delta G^{E}(\max )}{R T}=-0.8635 m^{2}\left(\alpha_{B}+\alpha_{C}\right)
$$

Some values of the excess free energy of mixing (in calories per kilogram of water, $1 \mathrm{cal}=4.1840 \mathrm{~J}$ are as follows:

$\begin{array}{lllllllll}m & 0.5 & 1.0 & 1.5 & 2.0 & 2.5 & 3.0 & 3.5 & 4.0 \\ \Delta G^{E}(\max ) & 1 & 2 & 4 & 6 & 8 & 7 & 6 & 0\end{array}$

These are remarkably small values. The value at $I=3, m=1,2$ cal per $\mathrm{kg}$ of water, can be compared with $-73,-35$, and -17 cal per $\mathrm{kg}$ of water for the systems water-hydrochloric acid-barium chloride, water-potassium chloride-barium chloride, and watersodium chloride-barium chloride, respectively [6]. It also compares with $79 \mathrm{cal}$ per $\mathrm{kg}$ of water for the system water-hydrochloric acid-sodium chloride [1] and -54 cal per $\mathrm{kg}$ of water for the system waterhydrochloric acid-potassium chloride [12].

\section{Vapor Pressure of Mixed Solutions}

It has been shown [13] that in many instances the vapor pressure lowering of a mixed solution can be compounded additively from the vapor pressure lowerings of the single salt solutions. For a system of the calcium chloride-magnesium chloride type, the variation in $a_{w}$ with change in composition at constant total ionic strength is given by [6]:

$127.82 \log a_{w}=127.82 \log a_{w_{(B)}}+3 \alpha_{B} m^{2} y_{C}$

$$
-\frac{3}{2}\left(\alpha_{B}+\alpha_{C}\right) m^{2} y_{C}^{2}-3\left(\beta_{C}-\beta_{B}\right) m^{3}\left(y_{C}^{2}-\frac{2 y_{C}^{3}}{3}\right)
$$

where $a_{w}\left(=p / p^{\circ}\right)$ is the water activity of the mixed solution and $a_{w_{(B)}}$ that of a solution containing calcium chloride only at the same total molality $m$.

If $\beta_{B}=\beta_{C}=0$,

$$
\begin{array}{r}
127.82 \log a_{w}=127.82 \log a_{w_{(B)}}+3 \alpha_{B} m^{2} y_{C} . \\
-\frac{3}{2}\left(\alpha_{B}+\alpha_{C}\right) m^{2} y_{C}^{2}
\end{array}
$$

and if $\alpha_{B}=-\alpha_{C}$,

$$
127.82 \log a_{w}=127.82 \log a_{w(B)}+3 \alpha_{B} m^{2} y_{C} .
$$

Thus, $\log a_{w}$ will be a linear function of $y_{C}$ and $a_{w}$ $\left(=p / p^{\circ}\right)$ will be very nearly a linear function of $y_{C}$. The additivity of vapor pressure lowerings is, therefore, to be sought in systems in which $\alpha_{B} \approx-\alpha_{C}$. Inspection of table 4 shows that this is very nearly true for the system calcium chloride-magnesium chloride. One example will illustrate this. From the known osmotic coefficients of calcium chloride solutions [11], it can be calculated that for a solution of concentration $4.1220 \mathrm{~m}, a_{w}=0.60836$. From set 12 of table 1 we see that this solution had the same water activity as a mixed solution of $m_{B}=2.3894$, $m_{C}=1.5948, m=3.9842, y_{C}=0.4003$. For this mixed solution, therefore, $\left(p^{\circ}-p\right) / p^{\circ}=0.39164$ and $\left(p^{\circ}-p\right)$ $=9.303 \mathrm{~mm} \mathrm{Hg}$. In the same way we calculate that for a solution of calcium chloride only at this total molality, $3.9842 m, a_{w}=0.62598$ and the vapor pressure lowering per mole is $\left(p^{\circ}-p\right) / m=2.230 \mathrm{~mm} \mathrm{Hg}$. We might then expect calcium chloride at molality $m_{B}=2.3894$ to contribute $5.328 \mathrm{~mm} \mathrm{Hg}$ to the vapor pressure lowering of the mixed solution. For a solution of magnesium chloride only at molality $3.9842 m$, we calculate $a_{w}=0.58212$ and $\left(p^{0}-p\right) / m$ $=2.491 \mathrm{~mm} \mathrm{Hg}$ so that we would expect magnesium chloride at molality $m_{C}=1.5948$ to contribute 3.973 $\mathrm{mm} \mathrm{Hg}$ to the vapor pressure lowering of the mixed solution. The sum of the two contributions, 9.301 $\mathrm{mm} \mathrm{Hg}$, is in very good agreement with the observed value of $9.303 \mathrm{~mm} \mathrm{Hg}$.

\section{Summary}

The behavior of the system calcium chloride-magnesium chloride is comparatively simple. At constant total ionic strength, the logarithm of the activity coefficient of either salt is, to a close approximation, a linear function of the concentration of the other salt. This is also true for the chemical potential of each salt. The activity coefficient of magnesium chloride is decreased by the addition of calcium chloride and, conversely, the activity coefficient of calcium chloride is increased by the addition of magnesium chloride. The "trace" activity coefficient of each salt is almost the same. This behavior is illustrated in figure 5 for a system at a constant total ionic strength of $I=12$. 
The Harned $\alpha_{B}$ and $\alpha_{C}$ coefficients, which express the relation between $\log \gamma$ for one salt and the concentration of the other salt, are almost equal in magnitude but opposite in sign. Consequently, the excess free energy of mixing of the system is very small and, moreover, the vapor pressure lowering of the mixed solution can be compounded almost additively from the vapor pressure lowerings of the separate salt solutions.

Grateful acknowledgment is made to the Office of Saline Water for a grant in partial support of this work.

\section{References}

[1] H. S. Harned, J. Phys. Chem. 63, 1299 (1959).

[2] R. A. Robinson, J. Phys. Chem. 65, 662 (1961).

[3] H. S. Harned and R. Gary, J. Am. Chem. Soc. 76, 5924 (1954).

[4] A. K. Covington, J. Chem. Soc. (London) 4906 (1965).

[5] R. A. Robinson and V. E. Bower, J. Res. NBS 69A (Phys. and Chem.) No. 1, 19 (1965).

[6] R. A. Robinson and V. E. Bower, J. Res. NBS 69A (Phys. and Chem.) No. 5, 439 (1965).

[7] J. M. Stokes and R. H. Stokes, J. Phys. Chem. 67, 2446 (1963).

[8] R. D. Lanier, J. Phys. Chem. 69, 3992 (1965).

[9] H. A. C. McKay and J. K. Perring, Trans. Faraday Soc. 49, 163 (1953).

[10] G. Marinenko and J. K. Taylor, J. Res. NBS 67A (Phys. and Chem.) No. 1, 31 (1963).

[11] R. A. Robinson and R. H. Stokes, Electrolyte Solutions, pp. 478-497, 2d ed., (Butterworths Scientific Publications, London, 1959).

[12] H. S. Harned, J. Phys. Chem. 64, 112 (1960).

[13] R. A. Robinson and V. E. Bower, J. Res. NBS 69A (Phys. and Chem.) No. 4, 365 (1965). 